\title{
The Application of Structural Equation Model in Location Selection and Spatial Layout of Convention and Convention and Exhibition Industry Cluster
}

\author{
Xinju Wu (Corresponding author) \\ School of Business, University of Shanghai for Science and Technology \\ 516 Jungong Road, Shanghai 200093, China \\ E-mail: lissawu@263.net \\ Sheng Li \\ School of Business, University of Shanghai for Science and Technology \\ 516 Jungong Road, Shanghai 200093, China \\ E-mail: oscarlisheng@gmail.com
}

The research is financed by University of Shanghai for Science and Technology

\begin{abstract}
The article is based on the theory of industry cluster's location selection and the authors discuss the formation mechanism of convention and convention and exhibition industry cluster by using the structural equation model. In addition, the authors analyze different elements, namely the regional factors which affect convention and exhibition industry cluster's location selecting, through making reference to Weber's theory of industrial location and neoteric and modern analysis methods of location theory. Moreover, the authors use structural equation model to discuss the causal relations between regional factor, supporting industry factor, infrastructure factor and level of convention and exhibition industry cluster. In the article, the latent variables, manifest variables and their causal relations in the structural equation model are determined. The authors aim to provide references for development route and district layout of convention and exhibition industry cluster.
\end{abstract}

Keywords: Convention and exhibition industry cluster, Regional factor, Structural equation model

\section{Introduction}

Convention and exhibition industry cluster is the symbol of maturity stage of convention and exhibition industry, it refers to the aggregate or convergent of companies, organizations, institutions or individuals who directly or indirectly engaging in convention and exhibition industry in a certain area. The core of the cluster is convention and exhibition industry, including the related service industry, advertisers, convention and exhibition agencies, hotels, market public relations institutions, institutes for convention and exhibition researching, training, and other related institutions and individuals. According to industrial characteristic, convention and exhibition industry cluster belongs to productive services industry cluster.

Convention and exhibition industry, acting as an important component of city or regional economy, has special requirement to the resources, not only natural resources, but also social and industrial resources. Therefore, location selection and directivity of location have great significance. The authors will give answer to the question: why convention and exhibition industry aggregate or convergent in a specific area, and which are the main region factors which attract convention and exhibition companies and other related companies to aggregate or convergent to the area.

\section{Foundation of theory}

Modern location theory is used to discuss space theorem and regular laws of human economic activities. It is also used to search for the best location for economic activities such as industry, agriculture and business, as well as to explore the relationships between location and economic activities. Since 20th century, the location theory has been experienced development processes from the theory of neoclassical location to the theory of behavior location, the theory of structural location, the theory of production methods location and then to the theory of 
imperfect competition location. Although these location theories have different research perspectives and methods, they are not absolutely opposite to each other. These theories have their own scopes of application and they are complimentary to each other to disclose the issue of industrial layout and different elements, which are namely the regional factors that affect organization's location selecting.

The guidance of traditional theories of industrial location to the convention and exhibition industry cluster is through the analysis of aggregation and corresponding aggregation factors. The theory of industrial location believes that aggregation and its dispersion factor not only make industry tend to centralize or decentralize because of reasons like division of responsibilities between each other or rise in price, but also they are the factors that create the offset effect on basic industrial location pattern decided by location condition. The aggregation factor is an 'advantage' which is not only the marketization created by the result of which the production to a large extent is brought to a certain location, but also the decrease in production or sales cost through concentration of production in the particular location to a certain amount. Weber's perspective based on industrial location is from the perspective of organization's location selection and it clarifies that whether or not an organization making a decision to select a location is relying on the comparison of benefit and cost. Weber divided factors that affect industrial location into nature, transportation, labor force, market factor, aggregation factor, dispersion factor, etc.

Neoteric and modern location theories have different genres. The guidance of these genres to the convention and exhibition industry cluster's location selection is manifest in emphasizing the perspectives of multiple factors to make continuously researches on regional economies and industrial layout, as well as having an overall consideration of relationships between each factor. The guidance also argues that making good use of limited space and resources can enhance the dynamic and coordinated development between the regions. The representational perspectives are as follows. The location and layout analysis of commercial service region advocated by Christaller's theory of central places; Market factor advocated by marketing location school's theories of market location represented by Losch; impact of government and regional condition of human on industrial economic activities advocated by Hoover's theory of competition layout; behavioral research on motivation and purpose of location selection's main body advocated by behaviorism, etc. It is shown that the research of modern location theory is beyond the research solely to the industrial location and it advocates analyzing industry cluster's location selection and layout through using the factor analysis. Since convention and exhibition industry is concerning numerous factors and many of which are hard to quantize. Therefore, the analysis methods of modern location theory have strong guidance to convention and exhibition industry cluster.

\section{Analysis of regional factors of convention and exhibition industry cluster}

According to the analysis of natural factors (regional factors) and aggregation factors in Weber's theory of industrial location and the factor analysis of industry cluster's location selecting from neoteric and modern theories of location, the authors argue that the factors affect convention and exhibition industry cluster's location selection are mainly including the following seven aspects. They are cost factor including transportation and labor force costs, market, behavior of organization's decision maker, organization structure and management approach of organization, social economic environment, transaction cost and economy of scale. These related regional factors can be classified into regional factor and aggregation factor. The regional factor refers to those factors suitable for convention and exhibition industry's development such as natural endowments, industrial factor or social economic environment, which were selected by organizations in industry cluster. The aggregation factor refers to the factors which have an influence on organization's centralization or decentralization. The transaction cost and economy of scale also play an important role in centralization and decentralization of organization. The authors divide the factors that affect transaction cost and economy of scale into two parts which are supporting industry factor and infrastructure factor. In this article, the authors will also analyze the factors which affect industry cluster's location selection through the analysis of structural equation model and how regional factor, supporting industry factor and infrastructure factor play the role in the formation of convention and exhibition industry cluster.

\section{Description of roadmap assumption and preliminary design of structural equation model}

According to $\mathrm{Wu}$ (2003, p.68), "Structural equation model is an analysis technique of multivariate statistics which constructing, estimating and inspecting model of causal relations, through considering inner structures of factors. The structural equation model consists of variables and relationships between them. The variables are divided into two kinds of variables which are construct variable and measurement variable. Construct variable, namely the latent variable, is a variable that reflects abstract and aggregate concept. Measured variable can also be called the manifest variable. Construct variable cannot be measured directly and it can only be measured and 
calculated by measured variable."

Structural equation model assumes the existence of causal relations between a group of latent variables and each of them can be represented by a group of manifest variables - the variables can be measured. Thus, the latent variable is the linear combination of several manifest variables. The coefficients of linear regression can be estimated through validating the covariance between manifest variables and therefore the model of assumption can be validated under statistics to find out whether it is appropriate for the research process. The authors use structural equation model to discuss causal relations between regional factor, industrial support factor, infrastructure factor and level of convention and exhibition industry cluster and determine the latent variables, manifest variables and roadmap assumption of causal relations between them. The correlations between variables are shown in Table 1.

From the above diagram that GDP of region, it is obvious that population scale and satisfaction of natural environment can be used to measure the regional factor. These variables are natural endowments of a certain location and they are the factors for convention and exhibition enterprises to consider when selecting the location at beginning. The measured variables for supporting industry factors are service industry based on consumption, financial industry and distributive service industry. The development conditions of these industries have an effect on the transaction cost and economy of scale of convention and exhibition industry which were also affected by the conditions of infrastructure. In the article, the variables like business infrastructure, information infrastructure and current area of convention and exhibition venue are being used to measure the conditions of infrastructure. The variables for evaluating level of convention and exhibition industry cluster can be measured by the amount and the output value of convention and exhibition industry.

\subsection{Roadmap assumption}

Figure 1 clearly shows the factors that affect convention and exhibition industry and causal relations between factors. We can witness from the Figure 1 that regional factor and infrastructure are natural endowments of a certain location and they are not being impacted obviously by the other variables with only having impact on them. Therefore, the regional factor and infrastructure are regarded as exogenous variables. However, supporting industry factor and level of convention and exhibition industry cluster are two variables which both impact on other variables and being impacted at same time and therefore they were regarded as endogenous variables. In the following paragraph, the direction of arrow demonstrates, which the start is cause and the end is effect, illustrates the causal relations between each factor.

Regional factor $\left(\xi_{1}\right) \longrightarrow$ Level of convention and exhibition industry cluster $\left(\eta_{1}\right)$

Supporting industry factor $\left(\eta_{2}\right) \longrightarrow$ Level of convention and exhibition industry cluster $\left(\eta_{1}\right)$

Infrastructure $\left(\xi_{2}\right) \longrightarrow$ Level of convention and exhibition industry cluster $\left(\eta_{1}\right)$

Infrastructure $\left(\xi_{2}\right) \longrightarrow$ Supporting industry factor $\left(\eta_{2}\right)$

\subsection{Structural equation and measured equation}

According to the roadmap assumption, the causal relations between the above variables can be represented by linear equations.

4.2.1 Structural equation

$$
\left[\begin{array}{l}
\eta_{1} \\
\eta_{2}
\end{array}\right]=\left[\begin{array}{cc}
0 & \beta_{21} \\
0 & 0
\end{array}\right]\left[\begin{array}{l}
\eta_{1} \\
\eta_{2}
\end{array}\right]+\left[\begin{array}{cc}
\gamma_{11} & \gamma_{21} \\
0 & \gamma_{22}
\end{array}\right]\left[\begin{array}{l}
\xi_{1} \\
\xi_{2}
\end{array}\right]+\left[\begin{array}{l}
\zeta_{1} \\
\zeta_{2}
\end{array}\right]
$$

$\beta$ represents the coefficient parameter between endogenous variables, $\gamma$ represents the coefficient parameter between endogenous variables, $\zeta$ represents error.

4.2.2 Measured equation

$$
\left[\begin{array}{l}
x_{1} \\
x_{2} \\
x_{3} \\
x_{4} \\
x_{5} \\
x_{6}
\end{array}\right]=\left[\begin{array}{ll}
\lambda_{1} & 0 \\
\lambda_{2} & 0 \\
\lambda_{3} & 0 \\
0 & \lambda_{4} \\
0 & \lambda_{5} \\
0 & \lambda_{6}
\end{array}\right]\left[\begin{array}{l}
\xi_{1} \\
\xi_{2}
\end{array}\right]+\left[\begin{array}{l}
\delta_{1} \\
\delta_{2} \\
\delta_{3} \\
\delta_{4} \\
\delta_{5} \\
\delta_{6}
\end{array}\right]
$$

$x$ represents the observed value of exogenous variable, $\lambda$ represents the coefficient parameter between 
measurement variable and exogenous variable, $\delta$ represents error.

$$
\left[\begin{array}{l}
y_{1} \\
y_{2} \\
y_{3} \\
y_{4} \\
y_{5}
\end{array}\right]=\left[\begin{array}{cc}
\lambda_{7} & 0 \\
\lambda_{8} & 0 \\
0 & \lambda_{9} \\
0 & \lambda_{10} \\
0 & \lambda_{11}
\end{array}\right]\left[\begin{array}{l}
\eta_{1} \\
\eta_{2}
\end{array}\right]+\left[\begin{array}{l}
\varepsilon_{1} \\
\varepsilon_{2} \\
\varepsilon_{3} \\
\varepsilon_{4} \\
\varepsilon_{5}
\end{array}\right]
$$

$y$ represents the observed value of endogenous variable, $\lambda$ represents the coefficient parameter between measurement variable and endogenous variable, $\delta$ represents error.

\subsection{Positive analysis}

15 comparatively advanced cities of convention and exhibition in China were selected and they are Beijing, Shanghai, Tianjin, Guangzhou, Shenzhen, Dalian, Qingdao, Hangzhou, Shenyang, Chongqing, Nanjing, Xiamen, Chengdu, Xian and Wuhan. The related data were normalized by using the equation either $\frac{x_{i}-x_{\min }}{x_{\max }-x_{\min }}$ or $\frac{y_{i}-y_{\min }}{y_{\max }-y_{\min }}$

$y_{\max }-y_{\min }$. The results are shown in Table 2. The original data source of Table 2 is coming from (Yearbook, 2008, p.350), (Yearbook, 2008, p.530), (China Exposition Website, 2008) and (Ni, 2008, p.291).

Running the AMOS software by using the above related data of 15 cities and the results are shown in Table 3 and Figure 2 .

\subsection{Evaluation of model}

The results coming from software running shows that when parameter estimation of latent variables is at $1 \%$ significance level, relationship between each latent variable has statistic significance and causal relations between each latent variable are accordance with the research hypothesis suggested by the article.

Assuming that the convention and exhibition industry cluster is hidden variable, the construct of model of convention and exhibition industry cluster in the article educes the three main factors of convention and exhibition industry through exploratory factor analysis, so as to find out causal relations and effects from these three main factors to construct the model. It can be deduced from the model that there exist certain causal relations between convention and exhibition industry cluster and the conditions such as regional resources and economies. Furthermore, the model shows that convention and exhibition industry cluster is the consequence of nonlinear superposition of several factors. The analysis is as follows:

\subsubsection{Infrastructure factor}

The infrastructure factor has both direct and indirect causal relations to level of convention and exhibition industry cluster and moreover, it has the most significant direct impact on convention and exhibition industry cluster.

\subsubsection{Regional factor}

The level of regional economies and fundamental industry level - GDP, population scale - consumer demand and market demand, and the quality of environment have a crucial effect on the development of convention and exhibition industry cluster.

\subsubsection{Supporting industry factor}

The supporting industry factor represents the overall development level of modern service industry. On one hand, the infrastructure level has an influence on the supporting industry factor. On the other hand, the supporting industry factor has an impact on level of convention and exhibition industry cluster.

\section{Conclusion}

\subsection{Industry cluster's location selection - city or region of advanced economy}

The location appropriate for convention and exhibition Industry cluster is obviously tending to be metropolis, economic center or provincial capital city, manufacturing or processing commercial intensive city, etc. To a large extent, the disparity of regional urbanization level causes the disparity of convention and exhibition development situation which are including the disparity of both development level and extent of cluster. 


\subsection{Centripetal force of industry cluster - infrastructure}

Different industry has its own unique way of cluster, such as technology city normally take universities and research institutions as the cluster center. While for convention and exhibition, the cluster center is often the convention and exhibition venue. Heavily invested convention venue, plus convenient transportation condition and complete matching industry, will be great attraction and under such centripetal force (we call the attraction 'centripetal force'), the economic factors such as convention and exhibition capital, labor and technology begin to move to work as a industry cluster, thus creates the effect of cluster.

The related infrastructures of convention and exhibition industry include advanced convention and exhibition venues, developed transportation networks consist of road, railway and aviation, well city landscaping and environmental protection, mature logistics transportation system and water and electric supplying system, complete service facilities of commerce, finance, convention and exhibition training and technology, etc. These infrastructures are the centripetal force of development of convention and exhibition industry and form the convention and exhibition cluster. The more advanced the convention and exhibition industry is, the more participates and exhibitors within the cluster are and the higher the requirements to infrastructures. The reason why the convention and exhibition industry in China has pretty mature development and a certain scale of cluster in big cities like Shanghai, Guangzhou, Beijing and Shenzhen, is because these cities have comparatively complete infrastructures.

\subsection{Software support system of industry cluster - related service industries}

Convention and exhibition industry is not an independent industry. The second part of the article has a detailed discussion of related main bodies of convention and exhibition industry and interaction between main bodies. Related service industries can be regarded as software support system of convention and exhibition industry cluster as infrastructure has been being regarded as the hardware foundation of convention and exhibition industry cluster.

Firstly, service industries such as retail, hotel, catering and recreation can satisfy the fundamental requirements of consumer groups and convention and exhibition exhibitors and visitors. Secondly, the comparatively mature development of related tourism in locality of convention and exhibition provides derived tourism products and services for convention and exhibition industry. Thirdly, the other widely existed service intermediaries in the market like advertiser, package printing, market consultancy, commercial service institution, mass media and so on, requires business development which is relying on convention and exhibition industry. Fourthly, the completeness and high efficient operation of market support system, which supports the trades between producers and buyers, requires the support and guarantee of financial industry and distributive service industry.

\subsection{Impulsion of industry cluster - low cost and economy of scale}

Concerning a certain kind of economic activity, different location provides different production condition. The economic activities which have similarity of location-oriented characteristics tend to gather in the region that has corresponding location condition, and thus the industry cluster is formed. As in the real economic life, those energy consuming oriented and labor intensive corporations are reducing the production cost by commonly selecting the location which has sufficient energy resources or it is either labor intensive or the origin place of raw materials. In the same manner, the convention and exhibition industry cluster is formed at the region which has corresponding location condition. In this way, convention and exhibition resources within the region can be integrated; the production cost can be reduced through ways like resource sharing and perfect division; the transaction cost can be saved by reducing the communication distances and realizing the rapidity and certainty of transaction.

Under the circumstances of imperfect competition and increasing returns, the economy of scale is the most important regional factor. The main factors of convention and exhibition industry gathering in a certain region also depend on the effects of the economy of scale. Owing to increasing returns to scale, corporations will consider the place of high market demand or convenient supply of input in location selection. However, such kind of place is also relying on the location selection of the other corporations.

In this way, the region which has regional factor, supporting industry factor and infrastructure factor will comprehensively be attractive to the entering of similar and related economic activities. Such attraction will lead to the accumulative causality effects through interactions made by the market between three aspects- increasing returns to scale, cost and the movement of factors of production. Moreover, the convention and exhibition economic activities will continuously gather at the region and the trend of it is enhancing through such accumulative causality effects, and finally the path dependence is created. 


\subsection{Layout of convention and exhibition industry in China - nonequilibrium and hierarchical development pattern}

Owning to radiation and promotion effects of convention and exhibition economy, a large amount of convention and exhibition centers have been constructed recently by governments in different districts. Unfortunately, it still cannot meet the demands of convention and exhibition market and the biggest current problem of convention and exhibition development in China is 'scale' without 'economy'.

According to Weber and Perroux's theory of the industry location and Losch and Taylor's theory of central place, the authors believe that the macro-layout of convention and exhibition industry in China should adopt the nonequilibrium and hierarchical layout pattern. Infrastructure factor, regional factor and supporting industry factor are the important foundations for selecting the central place of convention and exhibition industry cluster.

Nonequilibrium pattern refers to selectively distributing the limited resources to the regions with rich resources. For example, the city with tremendous convention and exhibition centers, the location with inter-depending condition, and the location has convention and exhibition carriers like complete transportation and communication, etc. Hierarchical development pattern requires each city to adjust measures to local conditions and tailor the convention and exhibition industry, instead of to compare unrealistically and compete blindly between each other or spending huge amount of money on the construction of high standard and oversized convention and exhibition venues. Through the comparison between each factor, we can witness that some cities are suitable for developing convention and exhibition industry with a certain scale and appropriate for incubating convention and exhibition industry cluster; some cities are appropriate to small scale or dispersive convention and exhibition industry according to local trade and convention and exhibition requirements; Some cities are more likely to promote sales of local commodities through convention and exhibitions by totally adhering to local industrial economy of manufacturing.

For instance, governments in some big cities or capital cities in Middle West region of China have spent huge amount of money on constructing oversized convention and exhibition venues. However, it is difficult for these cities to develop convention and exhibition industry cluster with a certain scale because of their lack of factors required by convention and exhibition such as aggregation factor, nature factor, etc. For another example, some middle sized cities located around Guangzhou are relying on manufacturing and processing industry for their economic development. Thus, convention and exhibition industry in these cities is only the accessorial service industry of local industrial economy and has not created the room for independent development. Obviously they do not have the regional advantage of developing convention and exhibition industry with a large scale.

\section{References}

Anderson, J. C, Gerbing D.W. (1988). Structural Equation Modeling in Practice: A Review and Recommended Two -Step Approach, Journal of Psychological Bulletin. 103 (3) :411-423.

China Exposition Website. (2008). Statistics of expositions in Chinese cities. [Online] Available: http:// www.expo-china.com/ (July 10, 2009).

Ni, P.F. (2008). Blue Book of Urban Competitiveness, Beijing: Social Sciences Academic Press, (Chapter 14).

Shen D.Y, Chen, Z.Y. (2008). Convention \& Exhibition Frontier Theory and Policy Consideration in China, Beijing: China commerce and Trade press (Chapter 4).

Wu, M.L. (2003). Structure Equation Model: AMOS operation and application. Chongqing: Press of Chongqing University, (Chapter 1).

Yearbook, C.S. (2008). Yearbook 2008 China cities. Beijing: China Statistics Press, (Chapter 5)

Yearbook, C.S. (2008). Yearbook 2008 China regional economics. Beijing: China Statistics Press, (Chapter 8).

Yu, S. J, Li Y. S. (2004). Study on the Forming Mechanisms of Industrial Cluster's Location Selection, Journal of China Soft Science 1,120-122.

Zeng, W. J. (2008). Modern Event Industry and the Economic Development. Chengdu: Press of Sichuan University, (Chapter 1). 
Table 1. Correlation table of roadmap assumption of convention and exhibition industry cluster

\begin{tabular}{|c|c|}
\hline Latent variable & Measured variable \\
\hline Regional factor $\zeta_{1}$ & GDP of region \\
\cline { 2 - 2 } & Population scale \\
\cline { 2 - 2 } Level of exhibition industry cluster $\eta_{1}$ & Satisfaction of natural environment \\
\cline { 2 - 2 } & Amount of exhibition \\
\hline \multirow{2}{*}{ Supporting industry factor $\eta_{2}$} & Service industry based on consumption \\
\cline { 2 - 2 } & Financial industry \\
\cline { 2 - 2 } & Distributive service industry \\
\hline Infrastructure factor $\zeta_{2}$ & Business infrastructure \\
\cline { 2 - 2 } & Information infrastructure \\
\cline { 2 - 2 } & Current area of exhibition venue \\
\hline
\end{tabular}

Table 2. Convention and exhibition industry index and regional factor index

\begin{tabular}{|c|c|c|c|c|c|c|c|c|c|c|c|}
\hline Cities & $\begin{array}{l}\text { amount of } \\
\text { exhibition } \\
y_{1}\end{array}$ & $\begin{array}{l}\text { output value } \\
\text { of exhibition } \\
y_{2}\end{array}$ & $\begin{array}{l}\text { Service } \\
\text { industry } \\
\text { based on } \\
\text { consumption } \\
y_{3}\end{array}$ & $\begin{array}{l}\begin{array}{l}\text { financial } \\
\text { industry }\end{array} \\
y_{4}\end{array}$ & $\begin{array}{l}\text { distributive } \\
\text { service } \\
\text { industry } \\
y_{5}\end{array}$ & $\begin{array}{l}\text { information } \\
\text { infrastructure } \\
x_{4}\end{array}$ & $\begin{array}{l}\text { business } \\
\text { infrastructure } \\
x_{5}\end{array}$ & $\begin{array}{l}\text { area of } \\
\text { exhibition } \\
\text { venue } \\
x_{6}\end{array}$ & $\begin{array}{l}\text { GDP } \\
\text { region } \\
x_{1}\end{array}$ & $\begin{array}{c}\text { of } \begin{array}{l}\text { population } \\
\text { scale }\end{array} \\
x_{2}\end{array}$ & $\begin{array}{l}\text { satisfaction } \\
\text { of natural } \\
\text { environment } \\
x_{3}\end{array}$ \\
\hline Beijing & 0.664 & 1.000 & 0.602 & 0.800 & 0.711 & 0.574 & 0.503 & 0.880 & 0.759 & 0.793 & 0.649 \\
\hline Shanghai & 1.000 & 0.990 & 1.000 & 1.000 & 1.000 & 0.729 & 1.000 & 1.000 & 1.000 & 0.905 & 0.786 \\
\hline Tianjin & 0.109 & 0.314 & 0.312 & 0.275 & 0.254 & 0.196 & 0.672 & 0.273 & 0.421 & 0.628 & 0.578 \\
\hline Guangzhou & 0.668 & 0.627 & 0.453 & 0.426 & 0.547 & 0.488 & 0.621 & 0.895 & 0.586 & 0.503 & 0.631 \\
\hline Shenzhen & 0.303 & 0.494 & 0.587 & 0.363 & 0.564 & 1.000 & 0.881 & 0.260 & 0.561 & 0.130 & 0.622 \\
\hline Dalian & 0.104 & 0.203 & 0.172 & 0.160 & 0.594 & 0.180 & 0.498 & 0.126 & 0.248 & 0.379 & 0.881 \\
\hline Qingdao & 0.180 & 0.241 & 0.318 & 0.139 & 0.318 & 0.253 & 0.543 & 0.167 & 0.309 & 0.526 & 0.975 \\
\hline Hangzhou & 0.066 & 0.278 & 0.625 & 0.349 & 0.402 & 0.262 & 0.493 & 0.438 & 0.332 & 0.441 & 0.977 \\
\hline Shenyang & 0.047 & 0.223 & 0.168 & 0.141 & 0.946 & 0.145 & 0.281 & 0.173 & 0.243 & 0.466 & 0.574 \\
\hline Chongqing & 0.152 & 0.280 & 0.313 & 0.194 & 0.558 & 0.117 & 0.351 & 0.294 & 0.240 & 1.000 & 0.520 \\
\hline Nanjing & 0.071 & 0.239 & 0.391 & 0.274 & 0.411 & 0.155 & 0.523 & 0.212 & 0.268 & 0.402 & 0.693 \\
\hline Xiamen & 0.052 & 0.093 & 0.509 & 0.073 & 0.359 & 0.266 & 0.403 & 0.129 & 0.113 & 0.106 & 1.000 \\
\hline Chengdu & 0.123 & 0.241 & 0.371 & 0.195 & 0.548 & 0.280 & 0.332 & 0.453 & 0.265 & 0.730 & 0.718 \\
\hline Xian & 0.118 & 0.137 & 0.442 & 0.126 & 0.535 & 0.162 & 0.218 & 0.283 & 0.142 & 0.498 & 0.540 \\
\hline Wuhan & 0.081 & 0.229 & 0.337 & 0.197 & 0.738 & 0.203 & 0.404 & 0.170 & 0.250 & 0.542 & 0.608 \\
\hline
\end{tabular}


Table 3. Software operation result of AMOS

\begin{tabular}{|c|c|c|c|}
\hline & Estimate & C.R. & $\mathrm{P}$ \\
\hline supporting industry factor $\longleftarrow$ infrastructure & .958 & 2.578 & .010 \\
\hline level of exhibition industry cluster $\longleftarrow$ regional factor & .504 & 2.828 & .005 \\
\hline $\begin{array}{l}\text { level of exhibition industry cluster } \longleftarrow \text { supporting } \\
\text { industry factor }\end{array}$ & -3.041 & -.236 & .008 \\
\hline level of exhibition industry cluster $\longleftarrow$ infrastructure & $4.100 \backslash$ & .316 & $* * *$ \\
\hline e3 $\longleftarrow$ supporting industry factor & 1.000 & & \\
\hline e4 $\longleftarrow$ supporting industry factor & 1.609 & 4.732 & $* * *$ \\
\hline e5 $\longleftarrow$ supporting industry factor & .644 & 2.024 & $* * *$ \\
\hline e6 $\longleftarrow$ infrastructure & 1.000 & & \\
\hline e7 $\longleftarrow$ infrastructure & .741 & 2.227 & $* * *$ \\
\hline e8 $\longleftarrow$ infrastructure & 1.555 & 3.156 & *** \\
\hline el $\longleftarrow$ level of exhibition industry cluster & 1.000 & & \\
\hline e2 $\longleftarrow$ level of exhibition industry cluster & 1.011 & 7.898 & $* * *$ \\
\hline e9 $\longleftarrow$ regional factor & 1.000 & & \\
\hline e10 $\longleftarrow$ regional factor & .516 & 1.732 & $* * *$ \\
\hline e11 $\longleftarrow$ regional factor & -.174 & -.834 & $* * *$ \\
\hline
\end{tabular}

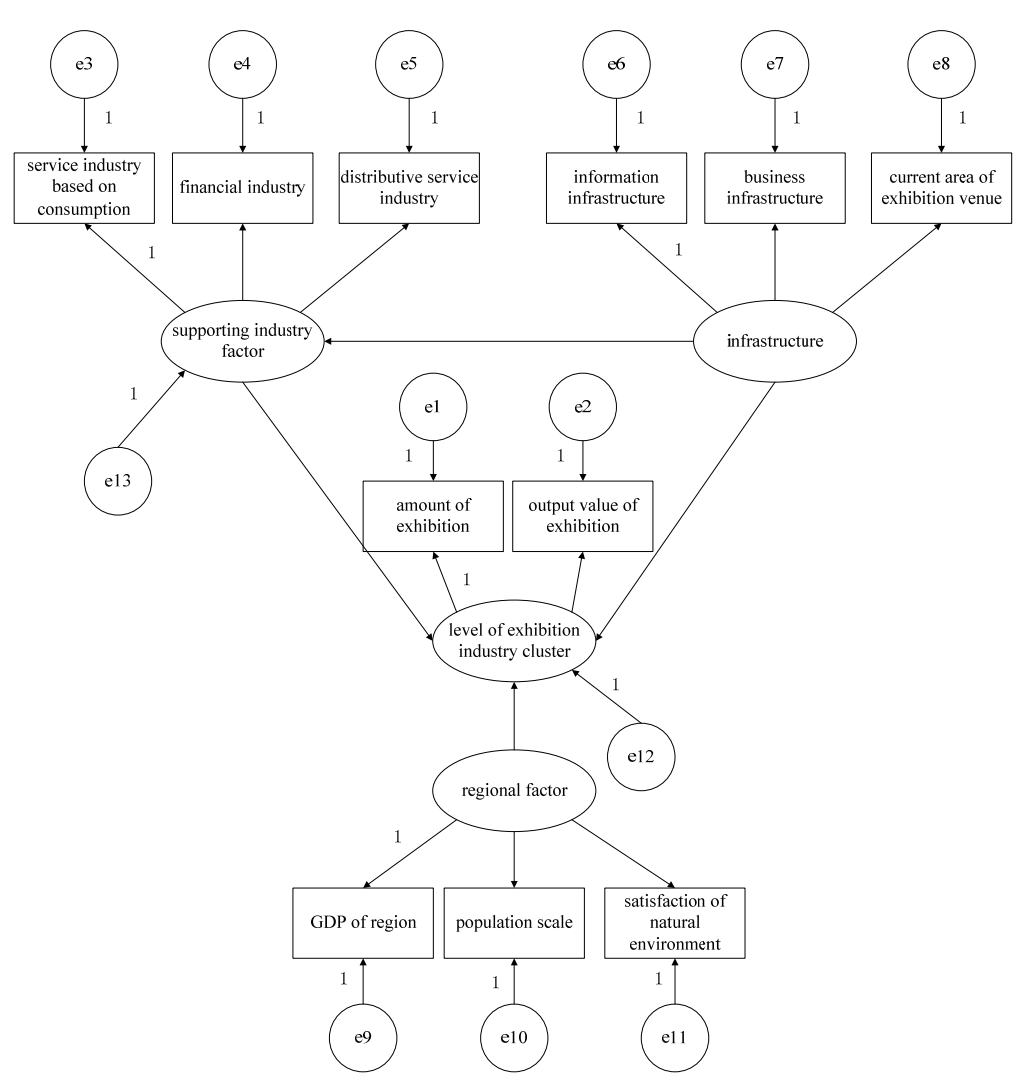

Figure 1. Roadmap Assumption of Structural Equation Model 


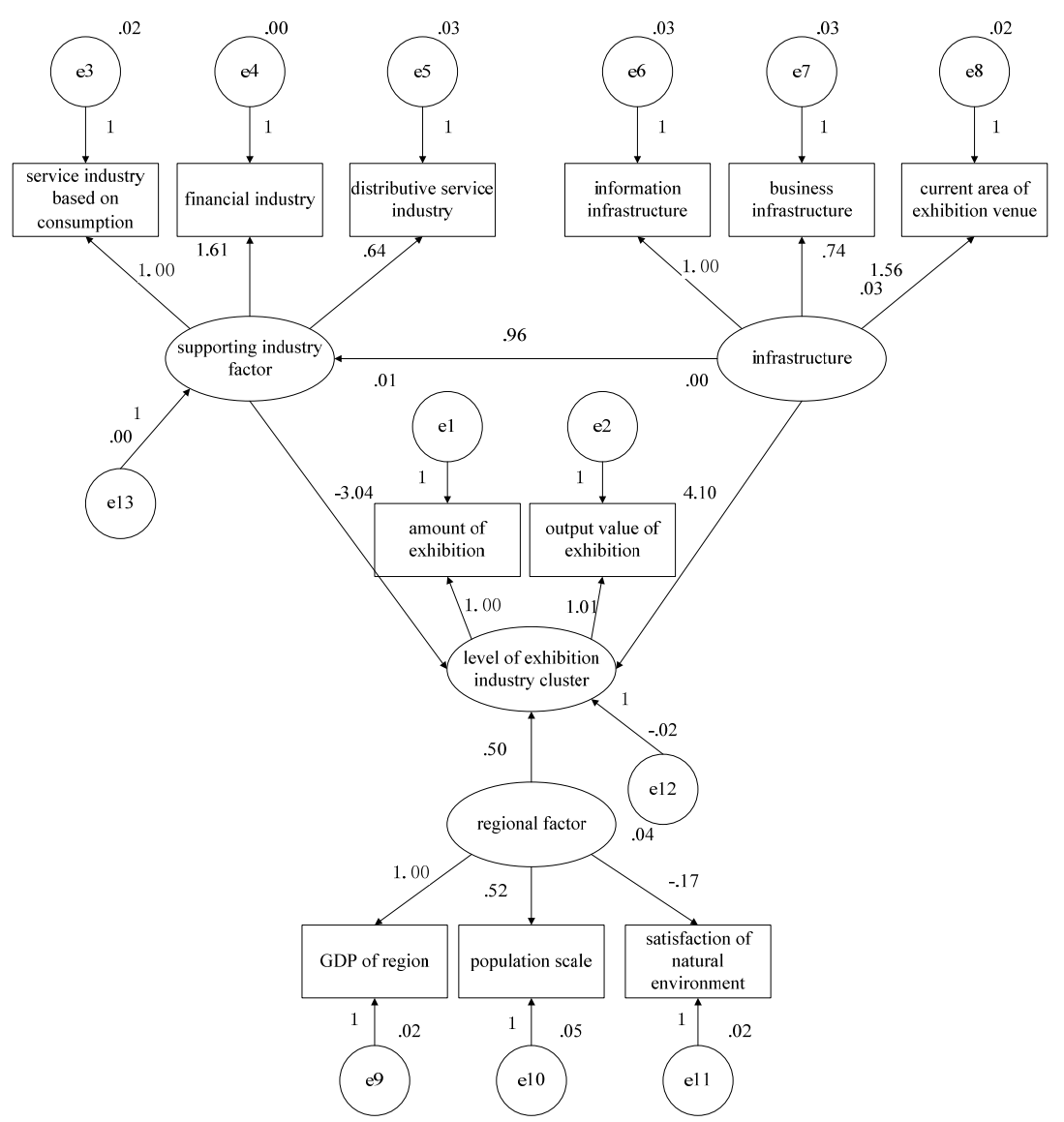

Figure 2. Software Operation Diagram of AMOS 